\title{
Fetal Station
}

National Cancer Institute

\section{Source}

National Cancer Institute. Fetal Station. NCI Thesaurus. Code C92717.

The relationship of the presenting part of the fetus to the maternal ischial spines during labor and delivery. 